\title{
Function Generation Synthesis of Planar Slider- Crank Linkages for Given 3 Positions and a Dead-Center Position
}

\author{
G. Kiper ${ }^{1}$, İ. Görgülü ${ }^{2}$ and S. F. Küçükoğlu ${ }^{3}$ \\ 'İzmir Institute of Technology,Turkey,e-mail: gokhankiper@iyte.edu.tr \\ ${ }^{2}$ Izmir Institute of Technology, Turkey, e-mail: ibrahimcangorgulu@iyte.edu.tr \\ ${ }^{3}$ İmir Institute of Technology,Turkey,e-mail: sefakucukoglu@iyte.edu.tr
}

Abstract.

Function generation for finitely many positions and dead-center design problems are generally separately handled in the literature. This paper presents a mixed formulation for planar slider-crank linkages where three precision points and a folded or extended dead-center position are to be satisfied. The formulation results in an $8^{\text {th }}$ degree univariate. Examples show that generally there are four real solutions, only two of which result in distinct solutions.

Keywords: Function generation synthesis, slider-crank linkage, finitely many positions, dead-center design.

\section{Introduction}

Designing linkages for given input/output requirements is formulated as a function generation synthesis problem. In most applications, finitely many desired values for the input/output joint variables of a linkage are given and link length dimensions are to be determined accordingly. Many textbooks issue only this type of function generation problem [1-3]. We shall call this problem as the function generation for finitely many positions. Another common problem in applications, which can be considered as a special case of function generation problem, is the dead-center design, where a desired limited range of output joint variable is specified for corresponding variation of the input joint variable. The linkage is designed to be at the dead-center position (DCP) at the limits of the output joint variable, where the output speed is instantaneously zero, hence it is dead. Hall [4] and Norton [5] treat the function generation for finitely many positions and the deadcenter design problems as separate problems. The dead-center problem is even 
treated as a fourth type of synthesis problem in addition to motion, path and function generation problems by Mallik et al. [6].

The planar four-bar and the planar slider-crank linkages are the two most commonly used linkages in applications used as function generators. There are several graphical and analytical methods for function generation synthesis of the four-bar and the slider-crank linkage in the literature. The analytical function generation synthesis methods for the four-bar and the slider-crank linkages for two and three prescribed positions and also the dead-center design problems were summarized by Pennestrì and Valentini [7]. The four-bar and slider-crank function generators can be designed for up to five precision points [3].

In some applications, it is required to design linkages for some specific values of the input/output joint variables and also one or more DCPs. Until recently such function generation synthesis problems formulated as a mixture of function generation for finitely many positions and dead-center design have not been noted in the literature. Although these problems can rapidly and easily be solved using CAD software, analytical formulations are necessary when these problems are merely a small part of a large design problem involving linkages with many loops and many link length parameters. Recently Kiper and Erez [8] formulated the analytical design equations for a planar four-bar function generator for two specified general positions and a DCP as the third position, where coupler link is folded upon one of the cranks whereas the other crank angle at this position is irrelevant. Similar problem for three positions can be addressed for a planar slider-crank linkage as well. In this paper, we extend our formulation for three general positions and a (folded or extended) DCP as fourth position for a slider-crank linkage.

\section{Design Equations}

Fig. 1 illustrates a general position and extended/folded DCPs of a planar slidercrank linkage. Crank length is a, coupler length is $b$, distance between linear path of joint $B$ and fixed joint $A_{0}$ is $d$ and the orientation angle of a fixed reference from which the crank angle is measured is $\alpha$. This angular link parameter, $\alpha$, may correspond to an angular link parameter connected to the crank or the fixed link, which needs to be designed as well. These four design parameters, a, b, $d$ and $\alpha$, are to be determined for 3 given general positions expressed in terms of pairs $\left(\theta_{1}\right.$, $\left.\mathrm{q}_{1}\right),\left(\theta_{2}, \mathrm{q}_{2}\right)$ and $\left(\theta_{3}, \mathrm{q}_{3}\right)$, and an extended or folded DCP, where only the output slider displacement, $\mathrm{q}_{\mathrm{e}}$ or $\mathrm{q}_{\mathrm{f}}$ is specified. 
Positions \#1,2,3
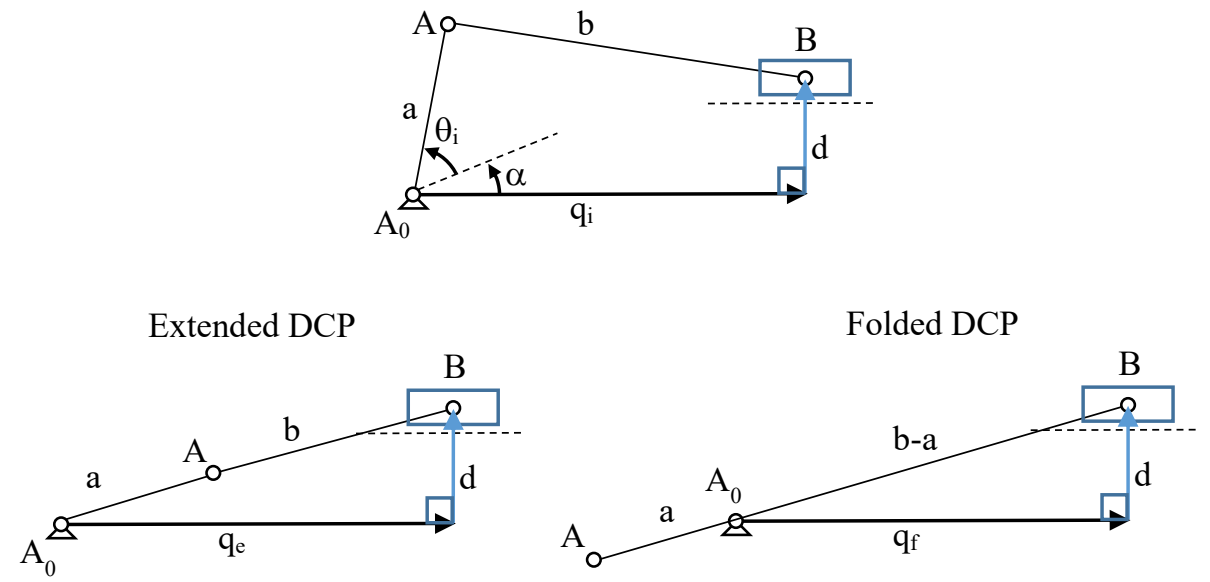

Fig. 1 A general position, extended and folded DCP of a slider-crank linkage

For a general position of the slider-crank linkage

$$
|\overrightarrow{\mathrm{AB}}|=\left|\overrightarrow{\mathrm{A}_{0} \mathrm{~B}}-\overrightarrow{\mathrm{A}_{0} \mathrm{~A}}\right| \Rightarrow \mathrm{b}^{2}=\left[\mathrm{q}_{\mathrm{i}}-\mathrm{a} \cos \left(\alpha+\theta_{\mathrm{i}}\right)\right]^{2}+\left[\mathrm{d}-\mathrm{a} \sin \left(\alpha+\theta_{\mathrm{i}}\right)\right]
$$

Let $\mathrm{c}_{\mathrm{i}}=\cos \left(\alpha+\theta_{\mathrm{i}}\right)$ and $\mathrm{s}_{\mathrm{i}}=\sin \left(\alpha+\theta_{\mathrm{i}}\right)$. Expanding and rearranging Eq. (1):

$$
\mathrm{b}^{2}-\mathrm{a}^{2}-\mathrm{d}^{2}+2 \mathrm{aq}_{\mathrm{i}} \mathrm{c}_{\mathrm{i}}+2 \mathrm{ads}_{\mathrm{i}}=\mathrm{q}_{\mathrm{i}}^{2}
$$

Let $P_{1}=b^{2}-a^{2}-d^{2}, P_{2}=2 a$ and $P_{3}=2 a d$. Eq. (2) is linear in $P_{1}, P_{2}$ and $P_{3}$. For given $\left(\theta_{1}, q_{1}\right),\left(\theta_{2}, q_{2}\right)$ and $\left(\theta_{3}, q_{3}\right), P_{1}, P_{2}$ and $P_{3}$ can be linearly solved from Eq. (2) as function of $\alpha$ :

$$
\begin{aligned}
& P_{1}+q_{1} c_{1} P_{2}+s_{1} P_{3}=q_{1}{ }^{2} \\
& P_{1}+q_{2} c_{2} P_{2}+s_{2} P_{3}=q_{2}{ }^{2} \\
& P_{1}+q_{3} c_{3} P_{2}+s_{3} P_{3}=q_{3}{ }^{2}
\end{aligned} \Rightarrow\left[\begin{array}{l}
P_{1} \\
P_{2} \\
P_{3}
\end{array}\right]=\left[\begin{array}{ccc}
1 & q_{1} c_{1} & s_{1} \\
1 & q_{2} c_{2} & s_{2} \\
1 & q_{3} c_{3} & s_{3}
\end{array}\right]^{-1}\left[\begin{array}{l}
q_{1}{ }^{2} \\
q_{2}{ }^{2} \\
q_{3}{ }^{2}
\end{array}\right]
$$

Using Cramer's rule: 


$$
\begin{gathered}
\mathrm{P}_{1}=\frac{\mathrm{q}_{1}^{2}\left(\mathrm{q}_{2} \mathrm{c}_{2} \mathrm{~s}_{3}-\mathrm{q}_{3} \mathrm{c}_{3} \mathrm{~s}_{2}\right)-\mathrm{q}_{2}{ }^{2}\left(\mathrm{q}_{1} \mathrm{c}_{1} \mathrm{~s}_{3}-\mathrm{q}_{3} \mathrm{c}_{3} \mathrm{~s}_{1}\right)+\mathrm{q}_{3}{ }^{2}\left(\mathrm{q}_{1} \mathrm{c}_{1} \mathrm{~s}_{2}-\mathrm{q}_{2} \mathrm{c}_{2} \mathrm{~s}_{1}\right)}{\mathrm{q}_{2} \mathrm{c}_{2} \mathrm{~s}_{3}-\mathrm{q}_{3} \mathrm{c}_{3} \mathrm{~s}_{2}-\mathrm{q}_{1} \mathrm{c}_{1} \mathrm{~s}_{3}+\mathrm{q}_{3} \mathrm{c}_{3} \mathrm{~s}_{1}+\mathrm{q}_{1} \mathrm{c}_{1} \mathrm{~s}_{2}-\mathrm{q}_{2} \mathrm{c}_{2} \mathrm{~s}_{1}} \\
\mathrm{P}_{2}=\frac{\left(\mathrm{q}_{3}{ }^{2}-\mathrm{q}_{2}{ }^{2}\right) \mathrm{s}_{1}+\left(\mathrm{q}_{1}{ }^{2}-\mathrm{q}_{3}{ }^{2}\right) \mathrm{s}_{2}+\left(\mathrm{q}_{2}{ }^{2}-\mathrm{q}_{1}{ }^{2}\right) \mathrm{s}_{3}}{\mathrm{q}_{2} \mathrm{c}_{2} \mathrm{~s}_{3}-\mathrm{q}_{3} \mathrm{c}_{3} \mathrm{~s}_{2}-\mathrm{q}_{1} \mathrm{c}_{1} \mathrm{~s}_{3}+\mathrm{q}_{3} \mathrm{c}_{3} \mathrm{~s}_{1}+\mathrm{q}_{1} \mathrm{c}_{1} \mathrm{~s}_{2}-\mathrm{q}_{2} \mathrm{c}_{2} \mathrm{~s}_{1}} \\
\mathrm{P}_{3}=\frac{\left(\mathrm{q}_{2}{ }^{2}-\mathrm{q}_{3}{ }^{2}\right) \mathrm{q}_{1} \mathrm{c}_{1}+\left(\mathrm{q}_{3}{ }^{2}-\mathrm{q}_{1}{ }^{2}\right) \mathrm{q}_{2} \mathrm{c}_{2}+\left(\mathrm{q}_{1}{ }^{2}-\mathrm{q}_{2}{ }^{2}\right) \mathrm{q}_{3} \mathrm{c}_{3}}{\mathrm{q}_{2} \mathrm{c}_{2} \mathrm{~s}_{3}-\mathrm{q}_{3} \mathrm{c}_{3} \mathrm{~s}_{2}-\mathrm{q}_{1} \mathrm{c}_{1} \mathrm{~s}_{3}+\mathrm{q}_{3} \mathrm{c}_{3} \mathrm{~s}_{1}+\mathrm{q}_{1} \mathrm{c}_{1} \mathrm{~s}_{2}-\mathrm{q}_{2} \mathrm{c}_{2} \mathrm{~s}_{1}}
\end{gathered}
$$

Solving for $\mathrm{a}, \mathrm{d}, \mathrm{b}^{2}$ (expressed as a function of $\alpha$ ):

$$
a=P_{2} / 2, d=P_{3} / P_{2}, b^{2}=P_{1}+a^{2}+d^{2} \text { or } b=\sqrt{P_{1}+a^{2}+d^{2}}
$$

For the extended/folded DCPs

$$
\begin{gathered}
(a+b)^{2}=q_{e}{ }^{2}+d^{2} \Rightarrow a^{2}+b^{2}-d^{2}-q_{e}{ }^{2}=-2 a b \\
(b-a)^{2}=q_{f}{ }^{2}+d^{2} \Rightarrow a^{2}+b^{2}-d^{2}-q_{f}{ }^{2}=2 a b
\end{gathered}
$$

In order not to have a square root expression ( $\mathrm{b}^{2}$ is given in Eq. (5)), taking square of Eq. (6):

$$
\left(a^{2}+b^{2}-d^{2}-q_{d c}^{2}\right)^{2}=4 a^{2} b^{2}
$$

where $\mathrm{q}_{\mathrm{dc}}$ is either $\mathrm{q}_{\mathrm{e}}$ or $\mathrm{q}_{\mathrm{f}}$. By taking square of Eq. (6), the solution formulation for the extended DCP and folded DCP problems becomes identical. Writing Eq. (7) terms of $\mathrm{P}_{1}, \mathrm{P}_{2}, \mathrm{P}_{3}$ and rearranging:

$$
\left(\mathrm{P}_{1}-\mathrm{q}_{\mathrm{dc}}^{2}\right)^{2}-\mathrm{P}_{3}^{2}-\mathrm{q}_{\mathrm{dc}}^{2} \mathrm{P}_{2}^{2}=0
$$

Eq. (8) is an equation in terms of $\alpha$ and can be numerically solved using a root finding algorithm. Then the corresponding $\mathrm{a}, \mathrm{b}$ and $\mathrm{d}$ values can be determined using Eq. (5). In order to find an upper bound for the number of roots let $t=\tan \frac{\alpha}{2}$ so that

$$
c_{i}=\frac{1-t^{2}}{1+t^{2}} \cos \theta_{i}-\frac{2 t}{1+t^{2}} \sin \theta_{i} \quad \text { and } \quad s_{i}=\frac{1-t^{2}}{1+t^{2}} \sin \theta_{i}+\frac{2 t}{1+t^{2}} \cos \theta_{i}
$$

Substituting Eq. (9) into Eq. (4) and substituting Eq. (4) into Eq. (8) results in an $8^{\text {th }}$ degree polynomial in $\mathrm{t}$. So there are at most 8 real solutions. 


\section{Computer Implementation}

The formulations in Section 2 were implemented in Excel (Fig. 2). The design inputs $\theta_{1}, \theta_{2}, \theta_{3}, \mathrm{q}_{1}, \mathrm{q}_{2}, \mathrm{q}_{3}, \mathrm{q}_{\mathrm{dc}}$ can be altered with the associated spin buttons. The matrix inversion in Eq. (3) for evaluating $\mathrm{P}_{1}, \mathrm{P}_{2}, \mathrm{P}_{3}$ is performed in cells A6:F8 for an assumed $\alpha$ value in cell H1. Eq. (8) is in cell F5. All spin buttons for the design inputs are associated with a single line code, which runs a Newton-Raphson method based goal-seek algorithm which seeks a suitable $\alpha$ value in cell H1 in order to make the cell F5 value equal to zero. That is, the equation is instantaneously solved when the design inputs are altered. In order to fasten the numerical solution, the slider displacement values are normalized to be around 1. The analysis of the resulting mechanism is performed and the mechanism can be animated.

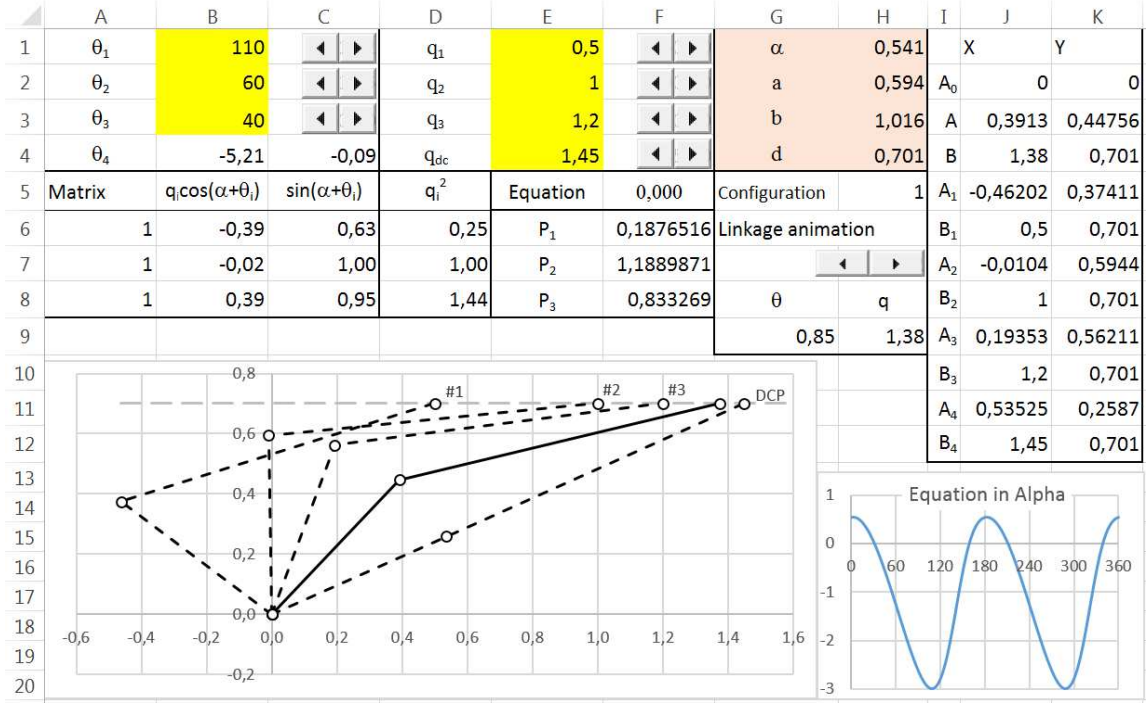

Fig. 2 Excel model

In order to see the number of roots of Eq. (8), the left hand side of the equation is plotted for $0^{\circ} \leq \alpha<360^{\circ}$. For several examples that were worked out, it is seen that generically there are 4 real roots. We observed that two of the solutions result in positive values of crank length a and the other two result in a negative a. Indeed the $\alpha$ solutions can be listed as $\alpha_{1}, \alpha_{2}, \alpha_{1}+180^{\circ}$ and $\alpha_{2}+180^{\circ}$. The $180^{\circ}$ angle difference results in positive or negative value of a. Also it can be noticed that the curve in Fig. 2 is $180^{\circ}$-periodic. Therefore, actually there are two solutions. Note that Eq. (8) holds for both folded and extended dead-center position problems. For the specific numerical example in Fig. 2, two solutions are found as $\alpha=31^{\circ}$ and $\alpha=328.8^{\circ}$ (or equivalently $-21.2^{\circ}$ ) result in feasible solutions. The linkage for 
$\alpha=31^{\circ}$ can be seen in Fig. 2, whereas the linkage for $\alpha=328.8^{\circ}$ is given in Fig. 3. The corresponding link lengths are listed in Table 1.

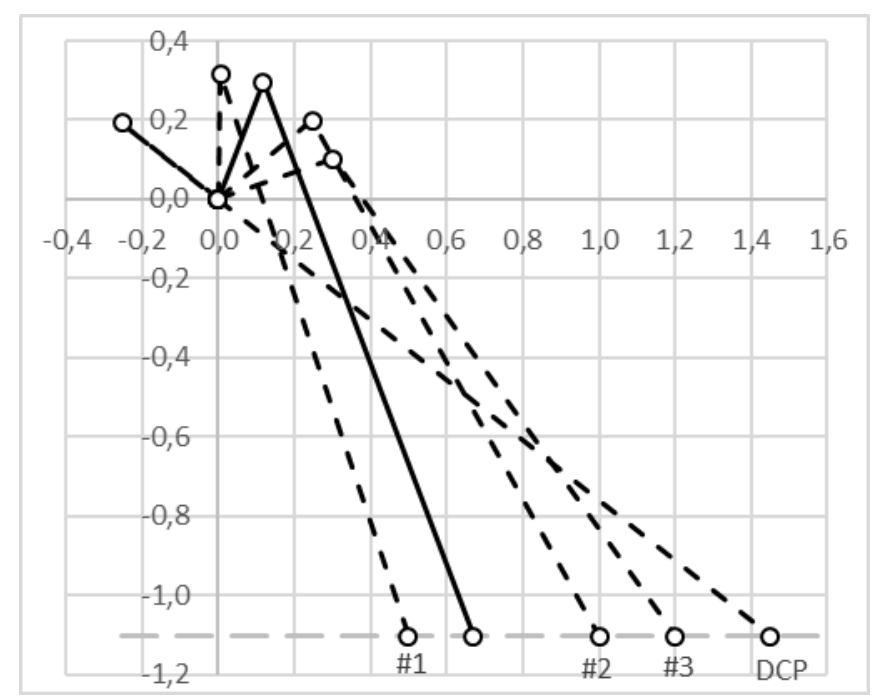

Fig. 3 Second solution for example 1

Several examples for 3 general positions and a folded DCP ( $\mathrm{q}_{\mathrm{cd}}$ should be less than $\mathrm{q}_{1}, \mathrm{q}_{2}, \mathrm{q}_{3}$ ) are also worked out. In order to have a comparable example with the one in Fig. 2, consider the case where $\theta_{1}=110^{\circ}, \theta_{2}=60^{\circ}, \theta_{3}=40^{\circ}, \mathrm{q}_{1}=0.5$, $\mathrm{q}_{2}=1, \mathrm{q}_{3}=1.2$ as in Fig. 2, but $\mathrm{q}_{\mathrm{cd}}=0.2$. Again two solutions for $\alpha$ are obtained as $\alpha=179.36^{\circ}$ and $\alpha=294.15^{\circ}$. Corresponding link lengths are listed in Table 1 . The resulting linkages are depicted in Fig. 4.

Table 1. Computed link length values for two examples

\begin{tabular}{|c|c|c|c|c|c|c|c|}
\hline \multirow{3}{*}{ Example 1} & $\theta_{1}$ & $\theta_{2}$ & $\theta_{3}$ & $\mathrm{q}_{1}$ & $\mathrm{q}_{2}$ & $\mathrm{q}_{3}$ & $\mathrm{q}_{\mathrm{dc}}$ \\
\hline & $110^{\circ}$ & $60^{\circ}$ & $40^{\circ}$ & 0.5 & 1 & 1.2 & 1.45 \\
\hline & \multicolumn{2}{|c|}{$\alpha$} & \multicolumn{2}{|l|}{$\mathrm{a}$} & \multicolumn{2}{|l|}{$\mathrm{b}$} & 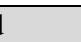 \\
\hline Solution 1 & \multicolumn{2}{|c|}{$-21.2^{\circ}$} & \multicolumn{2}{|c|}{0.318} & \multicolumn{2}{|c|}{1.504} & -1.103 \\
\hline Solution 2 & \multicolumn{2}{|c|}{$31^{\circ}$} & \multicolumn{2}{|c|}{0.594} & 1.016 & \multicolumn{2}{|c|}{0.701} \\
\hline \multirow{3}{*}{ Example 2} & $\overline{\theta_{1}}$ & $\theta_{2}$ & $\theta_{3}$ & $\mathrm{q}_{1}$ & $\mathrm{q}_{2}$ & $q_{3}$ & $\mathrm{q}_{\mathrm{dc}}$ \\
\hline & $110^{\circ}$ & $60^{\circ}$ & $40^{\circ}$ & 0.5 & 1 & 1.2 & 0.25 \\
\hline & \multicolumn{2}{|c|}{$\alpha$} & \multicolumn{2}{|c|}{$\mathrm{a}$} & $\mathrm{b}$ & \multicolumn{2}{|c|}{ d } \\
\hline Solution 1 & \multicolumn{2}{|c|}{$-2.55^{\circ}$} & \multicolumn{2}{|c|}{0.551} & 0.809 & \multicolumn{2}{|c|}{0.065} \\
\hline Solution 2 & \multicolumn{2}{|c|}{$117.4^{\circ}$} & \multicolumn{2}{|c|}{0.323} & 2.667 & \multicolumn{2}{|c|}{2.330} \\
\hline
\end{tabular}




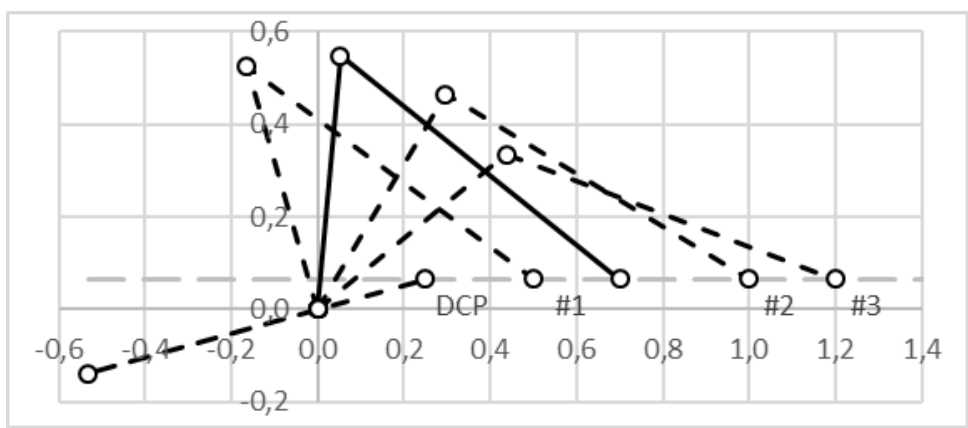

Fig. 4 First solution for example 2

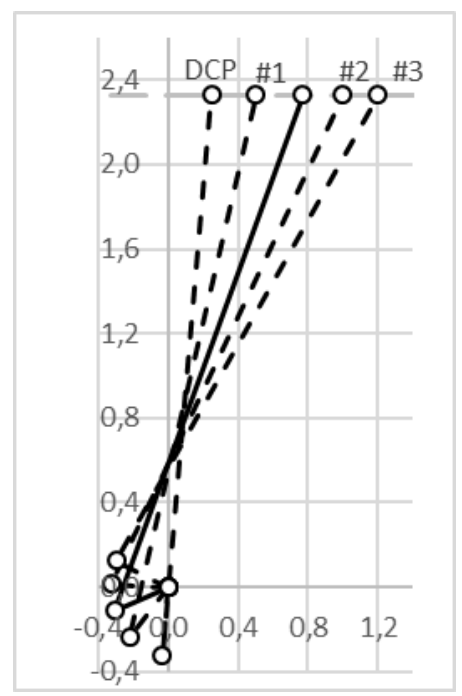

Fig. 5 Second solution for example 2

\section{Conclusions and Discussions}

In this paper, function generation problem for three precision points and a DCP is formulated for a slider-crank linkage. Similar formulations may be derived for other single loop linkages such as the four-bar and the inverted slider-crank. Also two precision points and two (folded and extended) DCPs can be considered. Such 
mixed function generation problems can also be handled for optimum transmission angle as well.

\section{References}

1. Hartenberg, R. S., Denavit, J.: Kinematic Synthesis of Linkages. McGraw-Hill, New York (1964).

2. Sandor, G. N., Erdman A. G., Advanced Mechanism Design: Analysis and Synthesis Vol. II. Prentice Hall, New Jersey (1984).

3. McCarthy, J. M., Soh, G. S.: Geometric Design of Linkages. $2^{\text {nd }}$ edn. Springer, New York (2011).

4. Hall, A. S.: Kinematics and Linkage Design. Prentice-Hall, Englewood Cliffs (1961).

5. Norton, R. L.: Design of Machinery. 6th edn. McGraw-Hill, Boston (2019).

6. Mallik, A. K., Ghosh, A., Dittrich, G.: Kinematic Analysis and Synthesis of Mechanisms. CRC Press, Boca Raton (1994).

7. Pennestrì, E., Valentini, P. P.: A review of simple analytical methods for the kinematic synthesis of four-bar and slider-crank function generators for two and three prescribed finite positions. In: Buletin Stiintific Seria Mecanica Aplicata, pp. 128-143. University of Pitesti, Pitești, (2009).

8. Kiper, G., Erez, M.: Function Generation Synthesis with Planar 4-Bar Linkage as a Mixed Problem of Correlation of Crank Angles and Dead-Center Design. In: Wang, D., Petuya, V., Chen, Y., Yu, S. (eds), Recent Advances in Mechanisms, Transmissions and Applications: Proceedings of the Fifth MeTrApp Conference 2019, Springer, 42-47 (2020) 